\title{
Time Variation in the Dynamics of Worker \\ Flows: Evidence from North America and
}

\section{Europe}

\author{
Michele Campolieti* \\ Department of Management, University of Toronto Scarborough \\ Centre for Industrial Relations, University of Toronto \\ Deborah Gefang \\ Department of Economics, Lancaster University \\ Gary Koop \\ Department of Economics, University of Strathclyde
}

October 2011, revised May 2012

\footnotetext{
${ }^{*}$ Campolieti gratefully acknowledges the financial support of the Social Sciences and Humanities Research Council of Canada (SSHRC) and helpful comments from participants at the Rimini Bayesian workshop. Please address correspondence to Michele Campolieti, Centre for Industrial Relations, University of Toronto, 121 St. George Street, Toronto, Ontario, M5S 2E8, Canada; email: campolie@chass.utoronto.ca. An online appendix to this paper is available at: http://personal.strath.ac.uk/gary.koop/campolieti_gefang_koop_appendix.pdf
} 


\begin{abstract}
VAR methods have been used to model the interrelationships between job vacancy rates, job separation rates and job-finding rates using tools such as impulse response analysis. In order to investigate whether such impulse responses change over the course of the business cycle or over time, this paper estimates TVP-VARs for data from North America (the US and Canada) and Europe (France, Spain and the United Kingdom). While the adjustment process of the labor market to shocks in Canada and the US is similar, there are some differences in the European countries. In Europe, we find the patterns in the adjustment process differ much more across countries, with the common feature across European countries being greater persistence in shocks relative to the US and Canada. We also find some evidence that the process of labor market adjustment can vary across time and the business cycle, especially in Europe.
\end{abstract}

JEL Classification: J64; J63; C32.

Keywords: job separation hazard, job-finding hazard, vacancies, labor market dynamics, time-varying parameter VAR, sign-restricted impulse responses 


\section{Introduction}

Changes in unemployment rates depend on both separation and job-finding rates (i.e. the flows into and out of unemployment). Understanding how unemployment is affected by both flows has a attracted a great deal of attention in the literature. Since the seminal work of Darby et al (1986), many studies have used descriptive measures to investigate the ins and outs of unemployment (e.g. Hall, 2005, Shimer, 2007, Elsby et al, 2009, Fujita and Ramey, 2006 and 2009, among many others). While this literature has primarily focused on the US, other countries, such as Canada (Campolieti, 2011) and European countries (Petrongolo and Pissarides, 2008, Elsby et al, 2008) have also been studied.

However, while these descriptive methods can be helpful in characterizing the separation and job finding rates as well as changes in unemployment rates, they do not take into account dynamics so they miss some important aspects of the adjustment process in the labor market. Arguing that descriptive measures may not be useful in disentangling shocks generated out of the labor market, such as productivity shocks, from those generated within the job search/matching system, Fujita (2011) uses VAR models to explore the interrelationships between the separation, job finding and vacancy rates in the US. He uses a structural VAR that is identified using the sign restriction approach of Uhlig (2005). In particular, he identifies a negative aggregate shock as one which causes changes to unemployment to be negative for $k$ quarters and does not immediately raise vacancies. This is the framework on which we build in the present paper.

The analysis of Fujita (2011) is conducted using a VAR with constant coefficients and, thus, impulse responses which are also constant. This can be potentially misleading if the mechanisms underlying the job search/matching process are varying over time. Results of many studies (e.g. Hall 2005, Shimer 2007, Elsby et al, 2009) suggest that the dynamics of the job finding and sepa- 
ration rates can be closely related to the fluctuations of business cycles. In the time series literature, many empirical papers (for example, Koop and Potter, 1999 and Skalin and Teräsvirta, 2002) find considerable evidence of nonlinearities in unemployment. To take account of these possible nonlinear effects, this paper extends Fujita (2011) by using a time-varying parameter (TVP) VAR. We adopt the TVP-VAR of Primiceri (2005) which additionally allows for multivariate stochastic volatility and is popular in the empirical macroeconomics literature. This framework is attractive since it allows both the VAR coefficients and the error covariance matrix to vary over time in a flexible and unrestricted fashion.

We estimate VARs and TVP-VARs using three series: the separation hazard (job separation rate); the job-finding hazard (job-finding rate); and, vacancy rates/indexes. We examine the dynamics of the labor market adjustment process in countries from North America (Canada and the US) and Europe (Spain, France and the United Kingdom). Our analysis allows us to compare and contrast how adjustments in the labor markets occur in these countries. Our empirical results provide support for the TVP-VAR with multivariate stochastic volatility. This support is particularly strong for the US, Spain and the UK. We also find support for the inequality restrictions we use to identify the impulse responses in all the countries we study. More specifically, despite the relatively weak restrictions we impose, our results provide a clear picture of how the labor market responds to these shocks in the five countries we consider.

Our results indicate that there are differences in how labor market adjustments occur in North America and Europe. For example, in Canada and the US we find that the separation hazard increases quickly after a shock before declining. In contrast, the job-finding hazard and vacancies in the US and Canada decrease after a shock in a hump shaped pattern. In Europe, we see differences 
across the countries we consider as well as compared to Canada and the US, since the patterns in the impulse responses tend to be country specific. The common feature of the impulse response functions for Europe, relative to those in the US and Canada, is that shocks tend to be more persistent and take much longer to decline as well as being much stronger during cyclical downturns. While we do not find much evidence of time variation in the impulse responses from France and Canada, we find some interesting time variation in the results for Spain, the UK and, especially, the US. For the US, while the impulse responses for most of the time periods we consider are similar, the impulse responses for the separation and job-finding hazard in the US Great Recession differ from those in earlier periods. In particular, the separation hazard responds more strongly to a shock and takes longer to dissipate. Furthermore, the job-finding hazard also responds more strongly initially and takes longer to decline and is still quite large at the end of the time horizon we consider. In Spain and the UK, we find that shocks tend to be much more persistent during cyclical downturns, since they take much longer to recover relative to other periods we consider. Interestingly, the impulse response functions for the US during the Great Recession are quite similar to those from Europe, in that they exhibit much more persistence. We also find some interesting differences in the size of the impulse responses for the job separation and job-finding hazard, which imply variation in the contributions to changes in unemployment, across countries and time. The impulse response functions for the job-finding hazard tend to be larger than those for the job separation hazard in the US and Canada, suggesting that the job-finding hazard will account for most of the changes in unemployment rates in the US and Canada. While earlier papers have found that the separation hazard plays a larger role in changes in unemployment in Europe, relative to Canada and the US, our TVP-VAR provides a more nuanced view of the role of the job-finding 
and job separation hazards in Europe. More specifically, our TVP-VAR allows us to determine that there is a great deal of variation in the roles of these hazard rates -both across time and the business cycle - in the European countries we study.

\section{Econometric Methods}

VAR methods have enjoyed wide popularity in empirical macroeconomics since the pioneering work of Sims (1980). VARs are atheoretical models which allow the researcher to investigate the relationships between time series variables without imposing any economic theory. Structural identifying restrictions are placed on VARs in order to give an economic interpretation to impulse responses and other features of interest. Traditionally, these identifying restrictions have been equality restrictions and, in some cases, have been criticized for being overly strong. Uhlig (2005) proposed using weaker sets of inequality restrictions in order to identify impulse responses. This attempt to impose the minimum amount of economic theory used, and let the data speak, is in the spirit of the atheoretical VAR literature. These considerations presumably motivated Fujita (2011), who used a VAR involving separation and job-finding hazards and vacancy rates along with a sign restriction approach. This approach required the

minimal assumptions that a negative shock cannot immediately raise vacancies and cannot cause the unemployment rate to fall for $k$ quarters.

Our econometric methods also begin with VARs with impulse responses being identified through similar sign restrictions. However, we also use TVP-VARs which allow for VAR coefficients to change over time. In empirical macroeconomics, there is a plethora of evidence of structural breaks and other kinds of parameter change (see, among many others, Stock and Watson, 1996) and this has led to a large number of papers which use TVP-VARs (see, among many 
others, Cogley and Sargent, 2001 and 2005, Cogley et al, 2005, Primiceri 2005, and D'Agostino et al, 2009, and Koop et al, 2009). It is also worth noting that most of these TVP-VAR papers allow for multivariate stochastic volatility which appears to be empirically important in many macroeconomic applications. One purpose of the present paper is to see whether TVP-VARs with multivariate stochastic volatility will prove equally useful in an analysis of the labor market.

In this section, we briefly outline the structure of TVP-VARs and describe how we implement the sign restriction approach to impulse response analysis. The online appendix provides additional details. Our TVP-VAR setup follows Primiceri (2005) and the sign restriction approach is implemented as in Uhlig (2005) and the reader is referred to these papers for additional motivation and explanation.

The basic VAR used by Fujita (2011) can be written as

$$
y_{t}=Z_{t} \theta+\varepsilon_{t},
$$

where $y_{t}$ is an $n \times 1$ vector of observations on the dependent variables, $Z_{t}$ is an $n \times m$ matrix defined so that each VAR equation contains an intercept and $p$ lags of all the dependent variables, and $\varepsilon_{t}$ are independent $N(0, H)$ for $t=1,2, \ldots, T$. The TVP-VAR extends this as

$$
y_{t}=Z_{t} \theta_{t}+\varepsilon_{t},
$$

where

$$
\theta_{t}=\theta_{t-1}+\eta_{t}
$$

and $\eta_{t}$ are independent $N(0, Q)$. Notice that this takes the form of a state space model and the time-varying VAR coefficients can be interpreted as an $m \times 1$ vector of unobserved states. This is a popular specification which allows for the 
coefficients to vary over time. It has the advantage that standard statistical methods for state space models can be used. In our empirical work, we refer to this as the homoskedastic TVP-VAR, to distinguish it from the heteroskedastic TVP-VAR which assumes $\varepsilon_{t}$ are independent $N\left(0, H_{t}\right)$. Following Primiceri (2005), we use a triangular decomposition to model $H_{t}$ :

$$
H_{t}=A_{t}^{-1} \Sigma_{t} \Sigma_{t}^{\prime}\left(A_{t}^{-1}\right)^{\prime}
$$

where $\Sigma_{t}$ is a diagonal matrix with diagonal elements $\sigma_{j, t}$ for $j=1,2, \ldots, n$ and $A_{t}$ is a lower triangular matrix with ones on the diagonal. That is, it takes the form:

$$
A_{t}=\left(\begin{array}{ccccc}
1 & 0 & \ldots & \cdot & 0 \\
a_{21, t} & 1 & \ldots & \cdot & \cdot \\
\cdot & . & \ldots & \cdot & \cdot \\
\cdot & . & \ldots & 1 & 0 \\
a_{n 1, t} & . & \ldots & a_{n(n-1), t} & 1
\end{array}\right)
$$

Let $\sigma_{t}=\left(\sigma_{1, t}, \sigma_{2, t}, \ldots, \sigma_{n, t}\right)^{\prime}$ and $a_{t}=\left(a_{21, t}, a_{31, t}, a_{32, t}, \ldots, a_{n(n-1), t}\right)^{\prime}$. These are allowed to evolve according to the following state equations:

$$
\log \left(\sigma_{t}\right)=\log \left(\sigma_{t-1}\right)+u_{t}
$$

and

$$
a_{t}=a_{t-1}+v_{t},
$$

where $u_{t} \sim$ i.i.d.N $(0, W), v_{t} \sim$ i.i.d.N $(0, C)$, and $u_{t}$ and $v_{t}$ are independent to each other with all the leads and lags. As discussed in Primiceri (2005), this specification is a flexible one, allowing both error variances and covariances to evolve over time.

Our empirical work considers VARs, homoskedastic TVP-VARs and het- 
eroskedastic TVP-VARs. We use the Bayesian information criterion (BIC) to compare these models. This can be interpreted as an asymptotic approximation to the log of the marginal likelihood (the conventional Bayesian model comparison metric). Note that BIC does not involve the prior, which is potentially an advantage in high-dimensional models such as VARs and TVP-VARs where marginal likelihoods can be sensitive to prior choice. Following Carlin and Louis (2000, Section 6), we calculate the BIC using the posterior expectation of the log-likelihood.

Additional technical details, including discussion of posterior simulation and the priors used in our Bayesian estimation procedure, are given in the online appendix. The reader is referred to Koop and Korobilis (2009) for complete details regarding Bayesian estimation of VARs and TVP-VARs.

The online appendix also gives details of how the sign-restricted impulse responses are calculated. We use the same methods as Uhlig (2005) and Fujita (2011). These require the specification of restrictions and we use the same restrictions as in Fujita (2011) which identify an aggregate shock using the following restrictions:

1. A negative aggregate shock will causes changes in unemployment to be non-negative for $k$ quarters.

2. A negative aggregate shock will not raise vacancies in the impact quarter.

In line with Fujita (2011), in this paper we set $k=2$. In the online appendix, we also present results for $k=1,3,4$ and find results to be fairly robust to choice of $k$. We present impulse responses for the three variables in $y_{t}$ (i.e. the separation and job-finding hazards and the vacancy rate). We also present a variance decomposition arising from the sign-restricted impulse response approach. Defined as in Fujita (2011), this measures the proportion of the forecast 
error variance at different horizons which can be attributed to the identified aggregate shock.

\section{Data}

We use quarterly data from the US (1951Q1 to 2009Q4), Canada (1981Q1 to 2003Q1), France (1995Q1 to 2007Q2), Spain (1987Q3 to 2005Q1) and the United Kingdom (1983Q3 to 2007Q2). We use the first 20 quarters of data from each country as a training sample and use the remaining data to estimate our models. The separation and job-finding hazards for France, Spain and the United Kingdom were obtained from Petrongolo and Pissarides (2008). The US data were obtained from Elsby et al (2010) and include the separation and job-finding hazard series, which were computed using data from the Current Population Survey (CPS). The Canadian separation and job-finding hazard series were originally computed in Campolieti (2011) using the public release files of the Labour Force Survey (LFS), which is collected by Statistics Canada and is comparable to the US CPS. The separation and job-finding hazard rates measure the flows into unemployment and out of unemployment. Details on the computation of the separation and job-finding hazards can be found in Elsby et al (2009), Elsby et al (2010), Campolieti (2011) and Petrongolo and Pissarides (2008).

For the US we use the vacancy series created by Barnichon (2010). This series combines information in the help wanted index collected by the Conference Board, which is based on help wanted ads in 51 prominent newspapers in the US, and the US Job Openings and Labor Turnover Survey (JOLTS). ${ }^{1}$ For Canada we use the help wanted index created by Statistics Canada, which is obtained from Statistics Canada's CANSIM database. ${ }^{2}$ The Canadian help wanted index

\footnotetext{
${ }^{1}$ The Job Openings and Labor Turnover Survey, which began to be collected during December 2000, contains information on the actual number of vacancies.

${ }^{2}$ This help wanted index was introduced during 1989 and was computed back to the first
} 
is based on the number of job ads in newspapers and is comparable to the US help wanted index data collected by the Conference Board. ${ }^{3}$ The vacancy rates (number of vacancies divided by number of openings) for France and Spain were based on data obtained from the OECD statistics portal, while the vacancy rate for the United Kingdom was computed based on data collected from the OECD statistics portal and ILO website.

Elsby et al (2010) computed their hazard rate series beginning in 1948, but the vacancy series in Barnichon (2010) begins in 1951, so our US sample period includes 1951Q1 to 2009Q4. While Campolieti (2011) computed hazard rate series for Canada from 1976Q1 to 2008Q4, the help wanted index for Canada begins in 1981Q1 and ends in 2003Q1, because Statistics Canada terminated the help wanted index for Canada in April 2003. The hazard rate series in Petrongolo and Pissarides (2008) are available for Spain from 1987Q3 to 2006Q3, for France from 1991Q1 to 2007Q2 and for the UK from 1983Q3 to 2007Q2. The lack of availability of more recent Spanish data for the vacancy rate limits our sample period to 1987Q3 to 2004Q4. We were also only able to obtain a vacancy rate for France beginning in 1995Q1, so that limited our sample for that country to $1995 \mathrm{Q} 1$ to $2007 \mathrm{Q} 2$. For the UK we were able use the whole period covered by Petrongolo and Pissarides (2007) hazard rate series.

We present plots of the raw data for the US, Canada, France, Spain and the UK in the online appendix. These plots indicate that there is some evidence of low-frequency trends in the data. Fujita (2011) argues that theoretical search/matching models are not associated with low-frequency trends and, accordingly, takes out such low frequency trends. Following Fujita (2011), we quarter of 1981.

${ }^{3}$ The help wanted index we use counts the number of job ads in Canada's 20 largest newspapers. There was also an earlier help wanted index that was available from 1962 to 1988. This index was proportional to the space occupied by job ads in Canada's 18 major newspapers, so it was sensitive to changes in fonts and column widths as well as paper size in the newspaper industry. 
detrend all our series using deterministic quadratic trends. ${ }^{4}$

\section{Empirical Results}

We divide our empirical results section into two sub-sections. The first describes discusses modelling choices and volatility estimates. The second sub-section presents impulse responses and variance decompositions.

\subsection{Model Comparison}

The BIC chooses VAR models with lag length 2 for the US, Canada and Spain, but lag length 1 for France and the UK. We adopt these choices for all of our VARs and TVP-VARs. With regards to the degree of time-variation in VAR coefficients and error variances, Table 1 presents BICs for three models. For notational convenience, we use 'Homo TVP-VAR' to denote TVP-VAR models with constant error covariance matrix, and 'Hete TVP-VAR' to denote TVP-VAR models with time varying error covariance matrix. Table 1 indicates moderately strong support for time-variation in both VAR coefficients and the error covariance matrix. That is, for all countries we study the Homo TVP-VAR has a substantially lower BIC than the VAR and the heteroskedastic TVPVAR in turn has a substantially lower BIC than the TVP-VAR. Accordingly, in the remainder of this paper we will focus mainly on the heteroskedastic TVPVAR. However, a complete set of results for all models is available in the online appendix.

\footnotetext{
${ }^{4}$ Results using non-detrended data are available in the online appendix. In general, results are similar to those presented in this paper. However, the impulse response functions for the non-detrended data tend to show more persistence in the shocks as well as bigger role for the separation hazard in the unemployment adjustment process in some of the countries we consider.
} 


\begin{tabular}{|l|c|c|c|c|c|}
\hline \multicolumn{7}{|c|}{ Table 1: BIC for Various Models } \\
\hline & US & Canada & France & Spain & UK \\
\hline VAR & 7.54 & 6.65 & 11.79 & 4.81 & 5.48 \\
\hline Homo TVP-VAR & -1.64 & -0.43 & -1.49 & 1.95 & -0.36 \\
\hline Hete TVP-VAR & -9.20 & -8.02 & -9.86 & -5.64 & -7.74 \\
\hline
\end{tabular}

With regards to the role of stochastic volatility, ${ }^{5}$ we note the following patterns. For Canada and the US, there is evidence of time variation in volatilities, but the patterns are quite different. For the longer US series, there are more peaks and troughs in the volatilities. For Canada, the time variation reveals itself largely through a spike around 1997. Campolieti (2011) noted that there is a spike in the separation hazard around 1997 and examined some other data sources for similar patterns. Campolieti (2011) concluded that the spike in the separation hazard was most likely related to a change in the wording of the temporary layoff question that was phased in between September 1996 and January 1997 (Sunter et al, 1997) that would classify more individuals as unemployed in the Canadian Labour Force Survey that occurred around this time, since the spike is not present in other data. Campolieti (2011) also observed an increase in the Canadian job-finding hazard around 1997. This increase in the rate at which the unemployed find jobs is equivalent to a decrease in unemployment duration, which is also seen in Macklem and Barrillas (2005). However, as noted in Campolieti (2011), the reasons for this increase in the job-finding rate from unemployment are unclear.

For France there is a very little evidence of stochastic volatility because the standard deviations take values in a very tight band for both hazard rates and the vacancy series. There is more evidence of stochastic volatility for Spain. In

\footnotetext{
${ }^{5}$ Figures which plot the posterior means of the standard deviations of the errors in the three equations of the TVP-VAR for the US, Canada, France, Spain and the UK are available in the online appendix
} 
particular, the error in the vacancy rate equation exhibits a number of spikes and troughs. The error in the job-finding hazard equation also exhibits some stochastic volatility, but this is more pronounced in the first half of the study period. For the UK the standard deviations for the separation and job-finding hazards fluctuate in a relatively narrow range. However, the UK vacancy rate exhibits more stochastic volatility.

\subsection{Impulse Response Functions and Variance Decompo- sitions}

For each country, we calculate impulse responses and variance decompositions for various time periods, choosing periods near troughs and peaks of the business cycle as well as including a period near the end of the sample. Choices of peaks and troughs are taken from the OECD recession indicators. For the US, we choose 1982Q4, 1992Q3, 2003Q2 (troughs), 1989Q2, 2000Q4 (peaks) and 2008Q2 (near the end of the sample). For Canada, we choose 1992Q4, 2002Q1 (troughs), 1989Q3, 2000Q2 (peaks) and 2003Q1 (end of sample). For the short French time series, we only consider 2001Q1 and 2003Q1 (troughs), 2007Q1 (peak, near the end of sample). For Spain, we choose 1995Q4, 2001Q1 (troughs), 1997Q1 and 2004Q1 (peaks, with the latter also being near the end of the sample). For the UK, we choose 1990Q4, 2001Q1 (troughs), 1999Q4, 2007Q1 (peaks, with the latter also being at end of the sample), .

\subsubsection{Variance Decompositions}

Before presenting impulse responses, we provide information that the sign restrictions used to calculate them are reasonable. Tables 2 through 6 present a summary of the variance decompositions for our five countries. ${ }^{6}$ The vari-

\footnotetext{
${ }^{6}$ Figures containing a full set of variance decompositions, including credible intervals, are available in the online appendix.
} 
ance decompositions were calculated up to a horizon of 20 quarters. The tables present the average of the point estimate over all horizons. These tables indicate that the aggregate shock we have identified accounts for an appreciable amount of the variability in all three of our variables. For the US, it accounts for roughly $38-44 \%$ of the variability in all three series. For Canada, comparable numbers are about 36-39\%. In France the variance decompositions are a little lower and lie between $27 \%$ and $32 \%$. In Spain and the UK, the variance decompositions are always above $40 \%$, which is slightly higher than for the US. These numbers are in line with those reported by Fujita (2011) in his constant coefficient VAR and are much larger than those in Uhlig (2005) in a different empirical application. ${ }^{7}$

Another diagnostic on the sign restriction approach is the percentage of the draws that satisfy the identification restrictions. These are presented in Tables 7 to 11. Paustian (2007), in his critique of the sign restriction approach, argued that the higher this percentage of draws is, the greater the likelihood that the correct signs of impulse responses are recovered. The acceptance rates we report in Tables 7 to 11 indicate that about 30 percent of the draws (and in some cases more) of the draws satisfy the restrictions.

Table 2: Average Variance Decomposition Rates for Hetero TVP-VAR, US

\begin{tabular}{|l|c|c|c|c|c|c|}
\hline Time & Q4 1982 & Q2 1989 & Q3 1992 & Q4 2000 & Q2 2003 & Q2 2008 \\
\hline Separation Hazard & 0.3777 & 0.3752 & 0.3725 & 0.3758 & 0.3781 & 0.3810 \\
\hline Job-Finding Hazard & 0.4326 & 0.4321 & 0.4267 & 0.4146 & 0.4154 & 0.4128 \\
\hline Vacancies & 0.4440 & 0.4361 & 0.4328 & 0.4270 & 0.4272 & 0.4262 \\
\hline
\end{tabular}

\footnotetext{
${ }^{7}$ Uhlig (2005) has been criticized by some for using weak restrictions and tended to find variance decompositions in the 5 to $15 \%$ range.
} 


\begin{tabular}{|l|c|c|c|c|c|}
\hline \multicolumn{5}{|c|}{ Table 3: Average Variance Decomposition Rates for Hetero TVP-VAR, Canada } \\
\hline Time & Q3 1989 & Q4 1992 & Q2 2000 & Q1 2002 & Q1 2003 \\
\hline Separation Hazard & 0.3633 & 0.3659 & 0.3828 & 0.3659 & 0.3766 \\
\hline Job-Finding Hazard & 0.3649 & 0.3675 & 0.3826 & 0.3675 & 0.3773 \\
\hline Vacancies & 0.3696 & 0.3726 & 0.3892 & 0.3726 & 0.3833 \\
\hline \hline
\end{tabular}

Table 4: Average Variance Decomposition Rates for Hetero TVP-VAR, France

\begin{tabular}{|l|c|c|c|}
\hline Time & Q1 2001 & Q1 2003 & Q1 2007 \\
\hline Separation Hazard & 0.2991 & 0.3002 & 0.3027 \\
\hline Job-Finding Hazard & 0.3099 & 0.3112 & 0.3142 \\
\hline Vacancies & 0.2752 & 0.2764 & 0.2793 \\
\hline \hline
\end{tabular}

Table 5: Average Variance Decomposition Rates for Hetero TVP-VAR, Spain

\begin{tabular}{|l|c|c|c|c|}
\hline Time & Q4 1995 & Q1 1997 & Q1 2001 & Q4 2004 \\
\hline Separation Hazard & 0.4513 & 0.4197 & 0.4513 & 0.4086 \\
\hline Job-Finding Hazard & 0.4495 & 0.4173 & 0.4495 & 0.4063 \\
\hline Vacancies & 0.4486 & 0.4189 & 0.4486 & 0.4078 \\
\hline \hline
\end{tabular}

Table 6: Average Variance Decomposition Rates for Hetero TVP-VAR, UK

\begin{tabular}{|l|c|c|c|c|}
\hline Time & Q4 1990 & Q4 1999 & Q1 2001 & Q1 2007 \\
\hline Separation Hazard & 0.4623 & 0.4466 & 0.4435 & 0.4291 \\
\hline Job-Finding Hazard & 0.4660 & 0.4535 & 0.4493 & 0.4394 \\
\hline Vacancies & 0.4524 & 0.4378 & 0.4333 & 0.4201 \\
\hline
\end{tabular}

Table 7: Acceptance Rate for the Number of Draws, US

\begin{tabular}{|l|c|c|c|c|c|c|}
\hline Time & Q4 1982 & Q2 1989 & Q3 1992 & Q4 2000 & Q2 2003 & Q2 2008 \\
\hline Hetero TVP-VAR & 0.4143 & 0.4090 & 0.4065 & 0.4034 & 0.4042 & 0.4048 \\
\hline
\end{tabular}

Table 8: Acceptance Rate for the Number of Draws, Canada

\begin{tabular}{|l|c|c|c|c|c|}
\hline Time & Q3 1989 & Q4 1992 & Q2 2000 & Q1 2002 & Q1 2003 \\
\hline Hetero TVP-VAR & 0.3589 & 0.3612 & 0.3721 & 0.3686 & 0.3667 \\
\hline
\end{tabular}




\begin{tabular}{|l|c|c|c|c|}
\hline \multicolumn{5}{|l|}{ Table 9: Acceptance Rate for the Number of Draws, France } \\
\hline Time & Q1 2001 & Q1 2003 & Q1 2007 \\
\hline Hetero TVP-VAR & 0.2760 & 0.2769 & 0.2783 \\
\hline Table 10: Acceptance Rate for the Number of Draws, Spain \\
\hline Time & Q4 1995 & Q1 1997 & Q1 2001 & Q4 2004 \\
\hline Hetero TVP-VAR & 0.2844 & 0.2790 & 0.2774 & 0.2609 \\
\hline \hline Table 11: Acceptance Rate for the Number of Draws, UK \\
\hline Time & Q4 1990 & Q4 1999 & Q1 2001 & Q1 2007 \\
\hline Hetero TVP-VAR & 0.3584 & 0.3525 & 0.3444 & 0.3311 \\
\hline
\end{tabular}

\subsubsection{Impulse Response Functions}

Figures 1 through 15 present impulse responses for the US, Canada, France, Spain and the UK. All of these figures are responses to the negative aggregate shock identified using the sign restrictions. The three figures for each country are responses of three variables (separation hazard, job-finding hazard and vacancy rate) to this shock at the time periods specified above. In all these figures the solid line is the posterior median and the dashed lines are the 16th and 84th percentiles of the posteriors. We present results only for the heteroskedastic TVP-VAR, but occasionally refer to results for other models. These latter results are available in the online appendix.

\section{The US}

The response of the separation hazard (Figure 1) to the aggregate shock dies off steadily and fairly quickly (in about 8 quarters). In contrast, the job-finding hazard and vacancy rate impulse responses exhibit hump-shaped patterns (Figures 2 and 3, respectively). These impulse responses tend to be near zero after about 12 quarters. These general patterns hold for most our time periods and also hold for the VAR and homoskedastic TVP-VAR. 
The signs of the responses for all the series we consider are unambiguous (i.e. the initial response to the shock has an error band that does not include zero), which provides support for the restrictions we use in the data. In other words, despite using weak restrictions, we observe the adjustment process in the US labor market quite clearly. The separation hazard (separation rate) reaches its peak quickly and then declines slowly. The job-finding hazard (job finding rate) and vacancies (see Figures 2 and 3) take a few quarters to reach a trough before starting to fade. The patterns in these series are like those in Fujita (2011). Moreover, they also support the conclusions in Elsby et al (2009) and Fujita and Ramey (2009) that unemployment dynamics in the US are driven by fluctuations in both the separation and job-finding hazard. However, the job-finding hazard does look to play a larger role than the separation hazard.

Overall, the differences across time periods do not appear to be too great, except for 2008Q2. However, there are some variations over time and differences with standard VAR results which are worth noting.

For the separation hazard, the impact impulse response found using the heteroskedastic TVP-VAR is larger than what is provided by the VAR. In addition, the impulse responses in 1982Q4 and 2008Q2 begin at a higher level and die away more steeply than for the other time periods.

For the job-finding hazard, the point estimate for the impulse responses is similar in each time period, but the credible interval between the 16th and 84th percentiles becomes wider over time, with the 2008Q2 interval being very wide.

For the vacancy rate, this pattern of wide credible intervals in 2008Q2 and a tendency of the impulse response function to take a long time to move towards zero, is also found. Other than this, impulse responses for this variable are quite similar in each time period and also similar to what is found for the standard VAR or homoskedastic TVP-VAR. Most of the time variation in the impulse 
responses is revealed in the initial response to a shock in 2008Q2, which is larger than that in the other time periods we consider.

The time variation in impulse responses is most visible in the impulse responses of the separation and job-finding hazard for 2008Q2. This is worth elaborating on since it provides some new insights into changes in the process of labor market adjustment in the US. We find that the impulse responses for the job-finding hazard for most of the periods we consider fade to zero, but the impulse responses for 2008Q2 are still large after 20 quarters. Elsby et al (2010) noted that there was an increase in the half-life of a deviation from steady state unemployment during the Great Recession relative to estimates of the half-life of a deviation from steady state unemployment obtained with data before the Great Recession (see also Elsby et al 2008; Elsby et al, 2009). In addition, Elsby et al (2010) also highlighted that there was an overall slowdown in the rate of exit from unemployment during the Great Recession resulting in an accumulation of long-term unemployed people. This accumulation of the long-term unemployed reduced the ability of the job-finding hazard in the US to rebound. Our impulse response functions for the job-finding hazard from 2008Q2 are consistent with these observations, while those from a conventional VAR model would not capture these effects. The impulse response for the separation hazard from 2008Q2 also tends to be larger than those for earlier periods and also takes longer to fade away. Elsby et al (2010) also found some evidence of elevated levels of job loss, relative to earlier recessions, during the Great Recession. In particular, they found evidence of more separations due to layoffs during the Great Recession. Our impulse responses for 2008Q2 would be consistent with this changed pattern observed by Elsby et al (2010).

The online appendix presents results for various priors and different choices for $k$ and these are found to be of the same pattern as those presented here. 

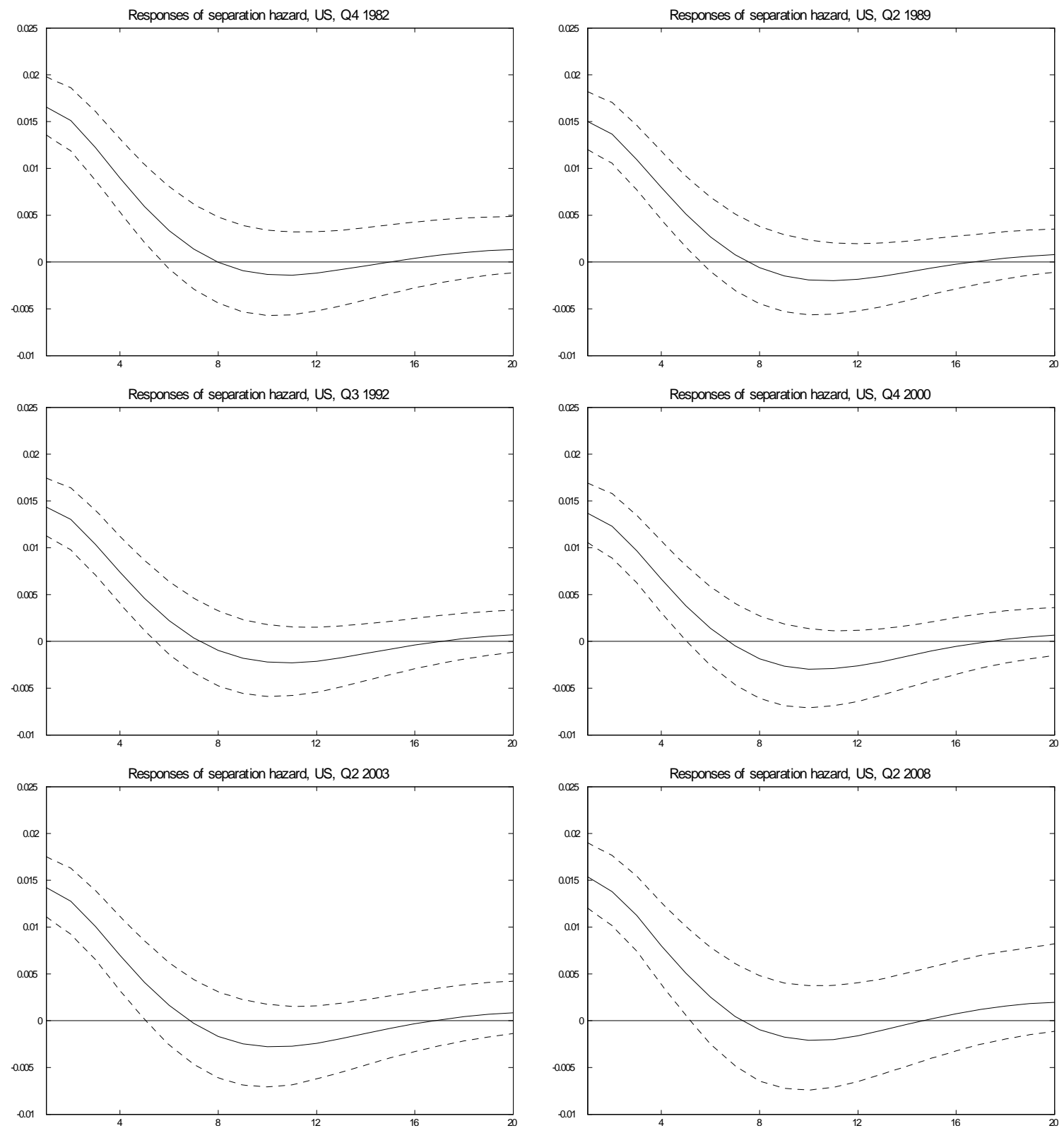

Figure 1. Impulse responses of separation hazards -Hete TVP-VAR, US 

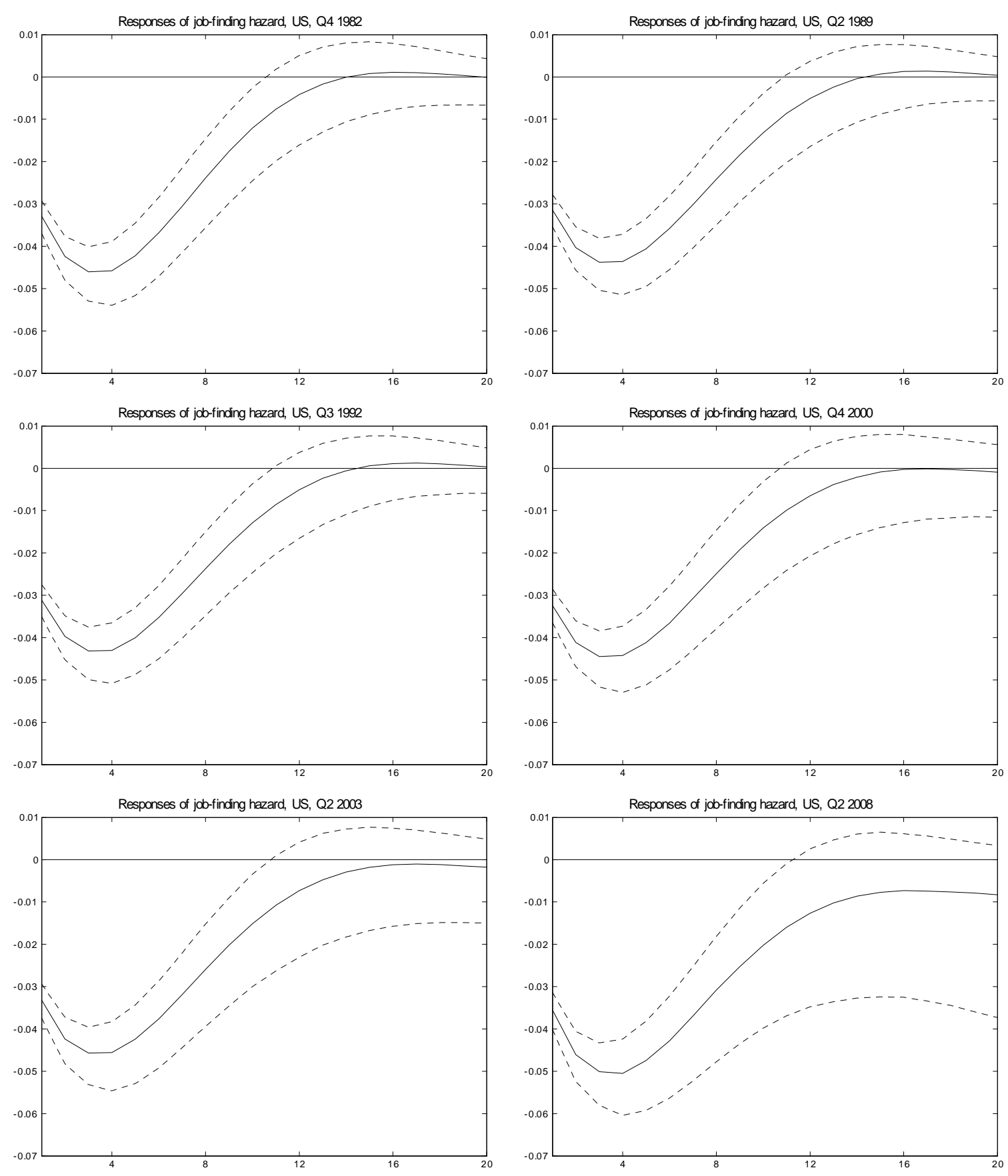

Figure 2. Impulse responses of job-finding hazards -Hete TVP-VAR, US 

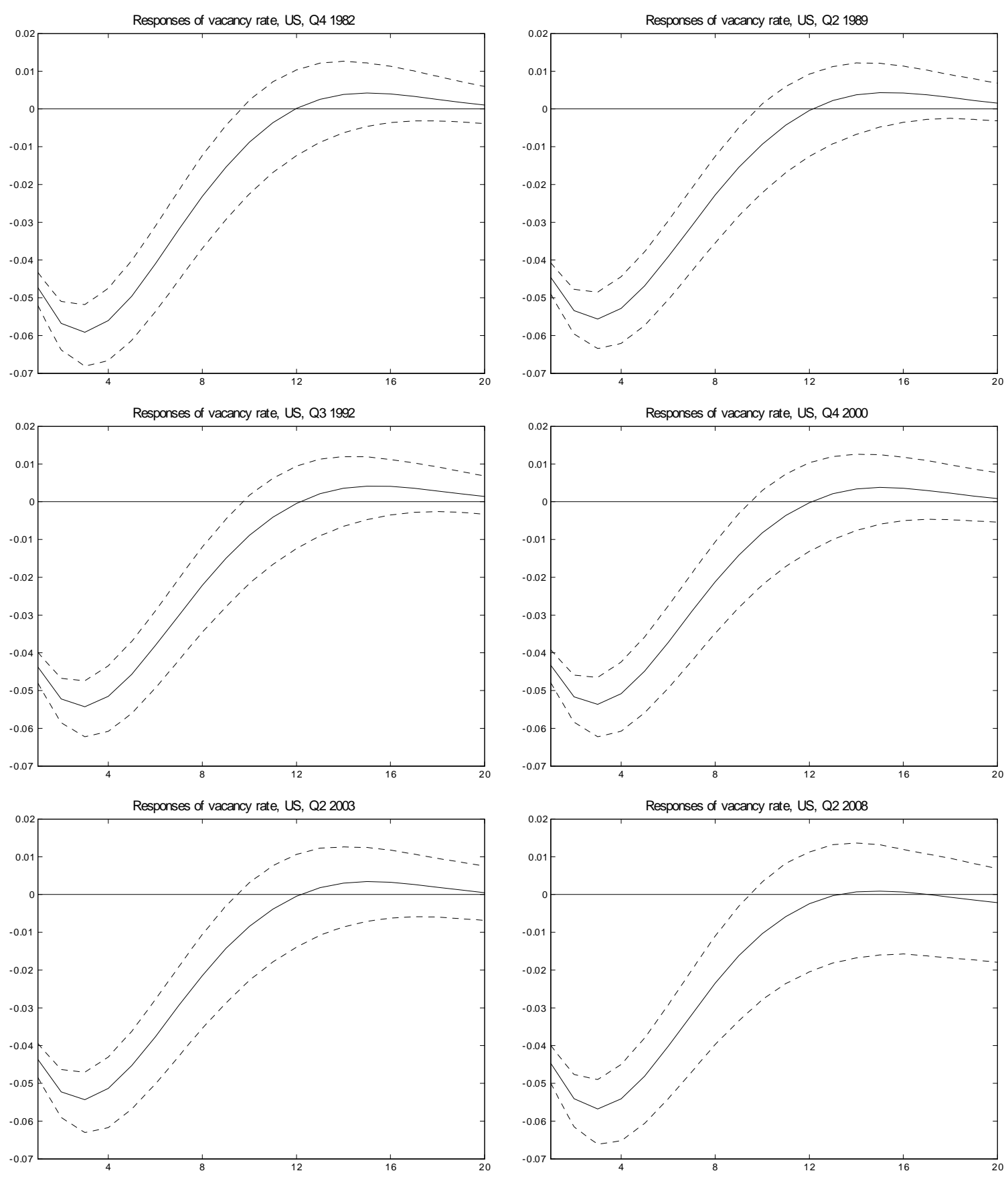

Figure 3. Impulse responses of vacancies - Hete TVP-VAR, US 


\section{Canada}

The general patterns found in the impulse responses using the Canadian data in Figures 4 to 6 are similar to those for the US. Impulse responses for the separation hazard do indeed die off in a similar manner as we found for the US. The impulse responses for the job-finding hazard and vacancies have a hump-shaped pattern, like their counterparts in the US, but tend to oscillate a little before fading. The previous statement holds for the point estimates of the impulse response, although the credible intervals are fairly wide and include the hump-shaped pattern. In addition, relative to the US, the impulse responses for the job-finding hazard do not have a trough that is as deep, but they do take longer to recover. The patterns in the impulse responses for the job-finding hazard, relative to the US, is interesting in the context of the difference in unemployment rates that has existed between the two countries since the early1980s (Riddell 2005). For most of the period we are considering the Canadian unemployment rate was higher than the US unemployment rate. The impulse responses for Canada, relative to the US, suggest that there could be lower exits from unemployment at longer horizons. This is consistent with observations made by Campolieti (2012), who found that changes in the job-finding hazard were responsible for a large part of the Canada-US unemployment rate gap.

In general, with Canadian data there is less evidence of time-variation in impulse responses for the separation and job-finding hazards and the vacancy rate. Although, for the separation hazard, there is some weak evidence that the effect of the negative aggregate shock is getting weaker over time. That is, impact responses are slightly less in 2002Q1 and 2003Q1 than in earlier years. ${ }^{8}$

\footnotetext{
${ }^{8}$ We present impulse responses for the unemployment rate in the appendix. These show that the impulse response in 1992Q4 for the unemployment rate is substantially different than those in other years. The impact and maximum responses are higher in this trough year than at other periods. While 1992Q4 is contained in the 1990-1992 recession, the period covered by the time horizon for the impulse responses corresponds to the period referred to as the 'The Great Canadian Slump' (Fortin 1996), which was a prolonged period of slow growth for the Canadian economy that extended into the mid-1990s following the end of the 1990-1992
} 
The similarity of the impulse responses for the periods we consider is like the pattern we observe in the US, except for 2008Q2. ${ }^{9}$ The Canadian estimates suggest that the response to a shock is similar across time and the business cycle. Also, like the US, the separation and job-finding hazards both play a role in the adjustment of the labor market, but the job-finding hazard effect is larger.

Results using different values for $k$ are similar to those presented here (see the online appendix). However, the results using the VAR or homoskedastic TVP-VARs do differ from those included here in some minor ways (e.g. the VAR results do not exhibit the same oscillatory responses noted above). Furthermore, the results are more sensitive to the prior than was found with the US data (although this is not unexpected due to the shorter data span). The reader is referred to the online appendix for full empirical results relating to these points.

recession.

${ }^{9}$ The Canadian data ends in $2003 \mathrm{Q} 1$ so we are not able to investigate the Canadian experience during the recession following the financial crisis of 2008 . 

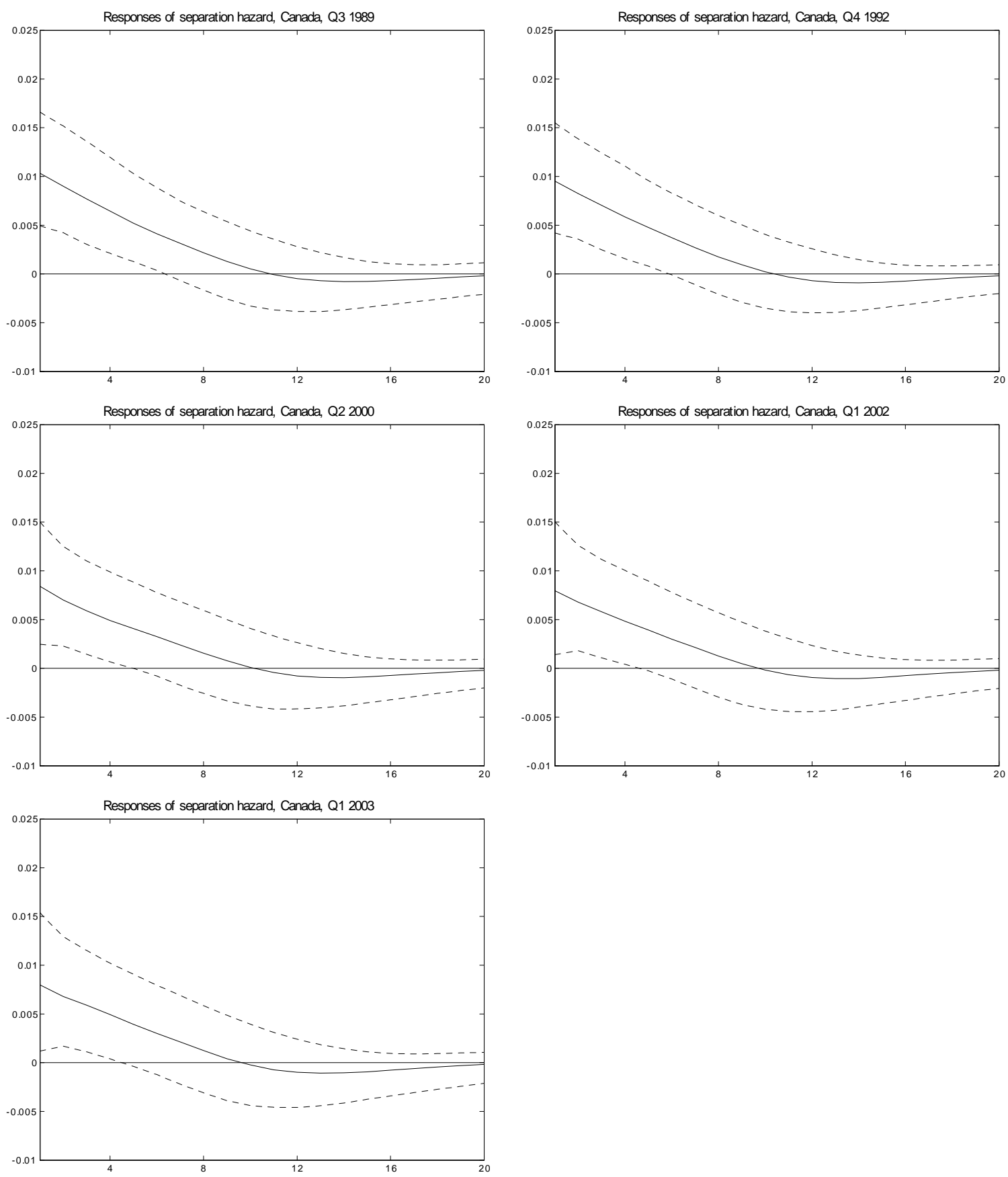

Figure 4. Impulse responses of separation hazards -Hete TVP-VAR, Canada 

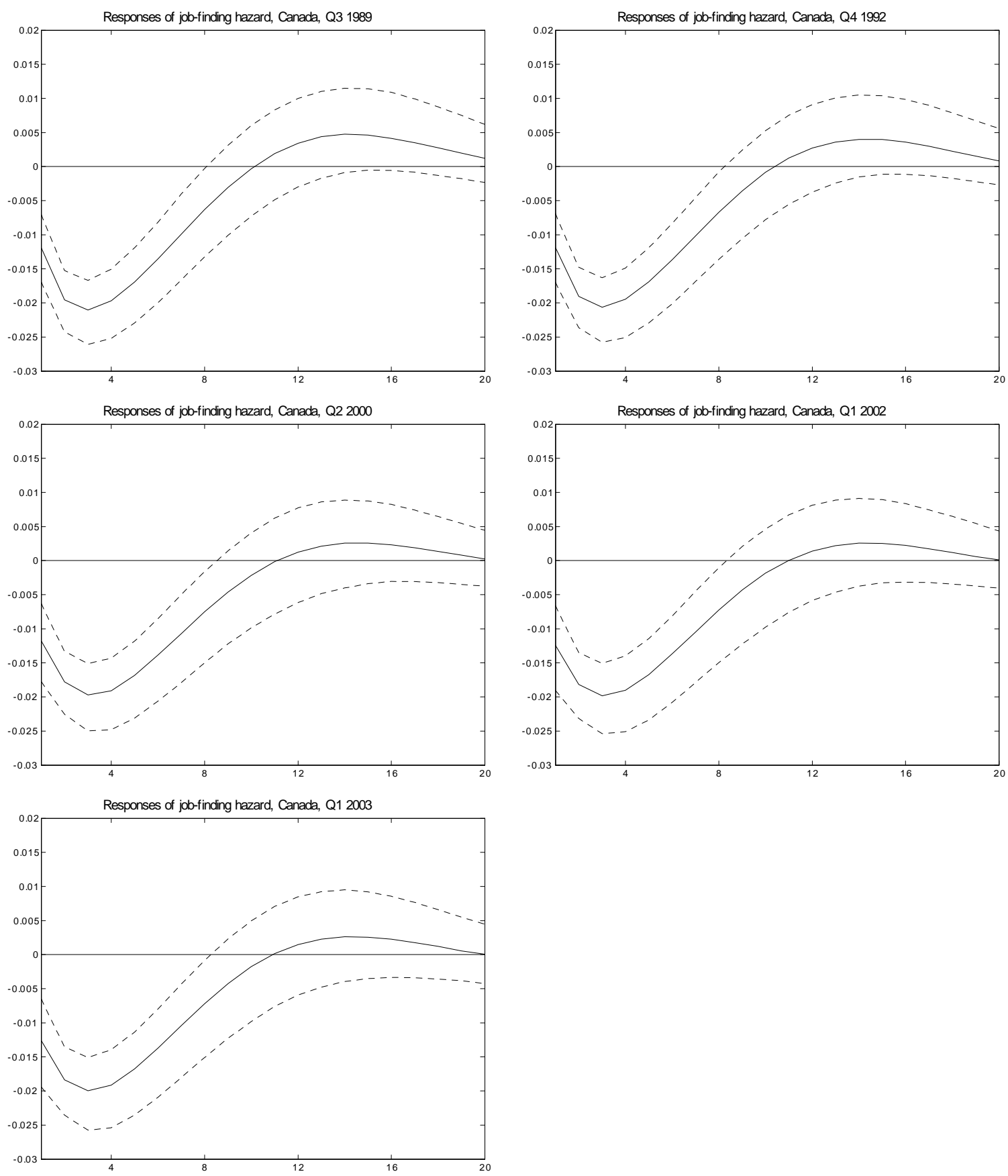

Figure 5. Impulse responses of job-finding hazards -Hete TVP-VAR, Canada 

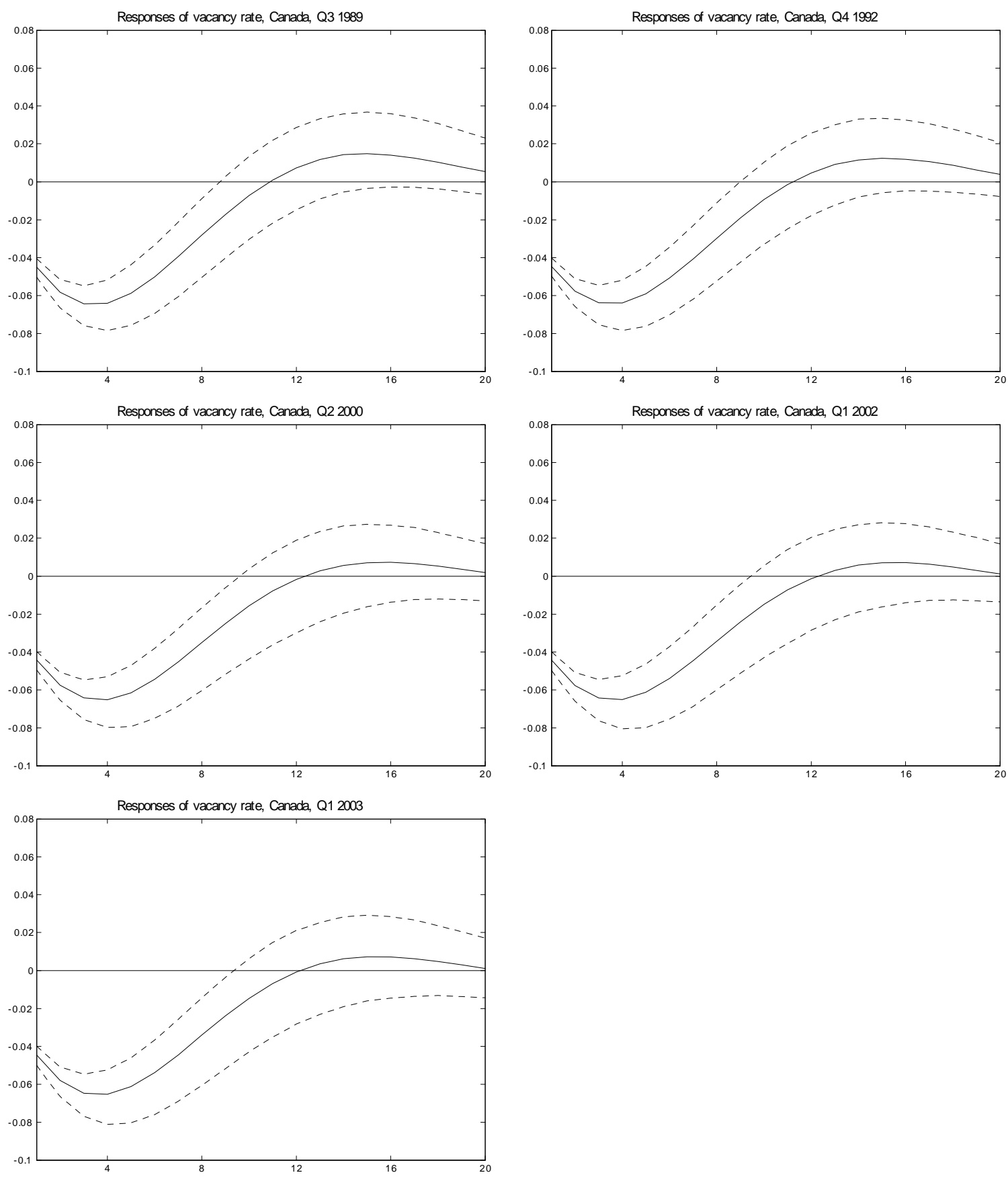

Figure 6. Impulse responses of vacancies -Hete TVP-VAR, Canada 


\section{France}

The impulse response functions for France are presented in Figures 7 to 9. The impulse responses for the separation hazard do not display a great deal of time variation in the three periods we consider for France. The impulse responses for separation hazards from France differ from those for the US and Canada in two ways. First, the impulse responses for the separation hazard have a bit of a hump shaped pattern, in that they increase slightly before beginning to decline. In contrast, for the US and Canada the impulse responses begin to decline after the initial period. Second, the impulse responses for France tend to take longer to fade away.

The impulse response functions for the job-finding hazard for France in Figure 8 also do not display much time variation, but our data comes from a relatively short window that does not include any deep recessions. Like those for the US and Canada, the impulse responses for the job-finding hazard have a hump shaped pattern. However, the impulse responses in France take longer to decline than those in Canada and the US, about 16 quarters versus 12 quarters for most of the periods (except for 2008Q2 in the US which is during the Great Recession).

The impulse responses for the vacancy rate for France also differs from those in the US and Canada. These impulse responses do not have a hump shaped pattern in France, like in the US and Canada, and tend to fade relative quickly (about 8 quarters, relative to Canada and the US, which take 10 to 12 quarters to decline in most of the periods we consider). 

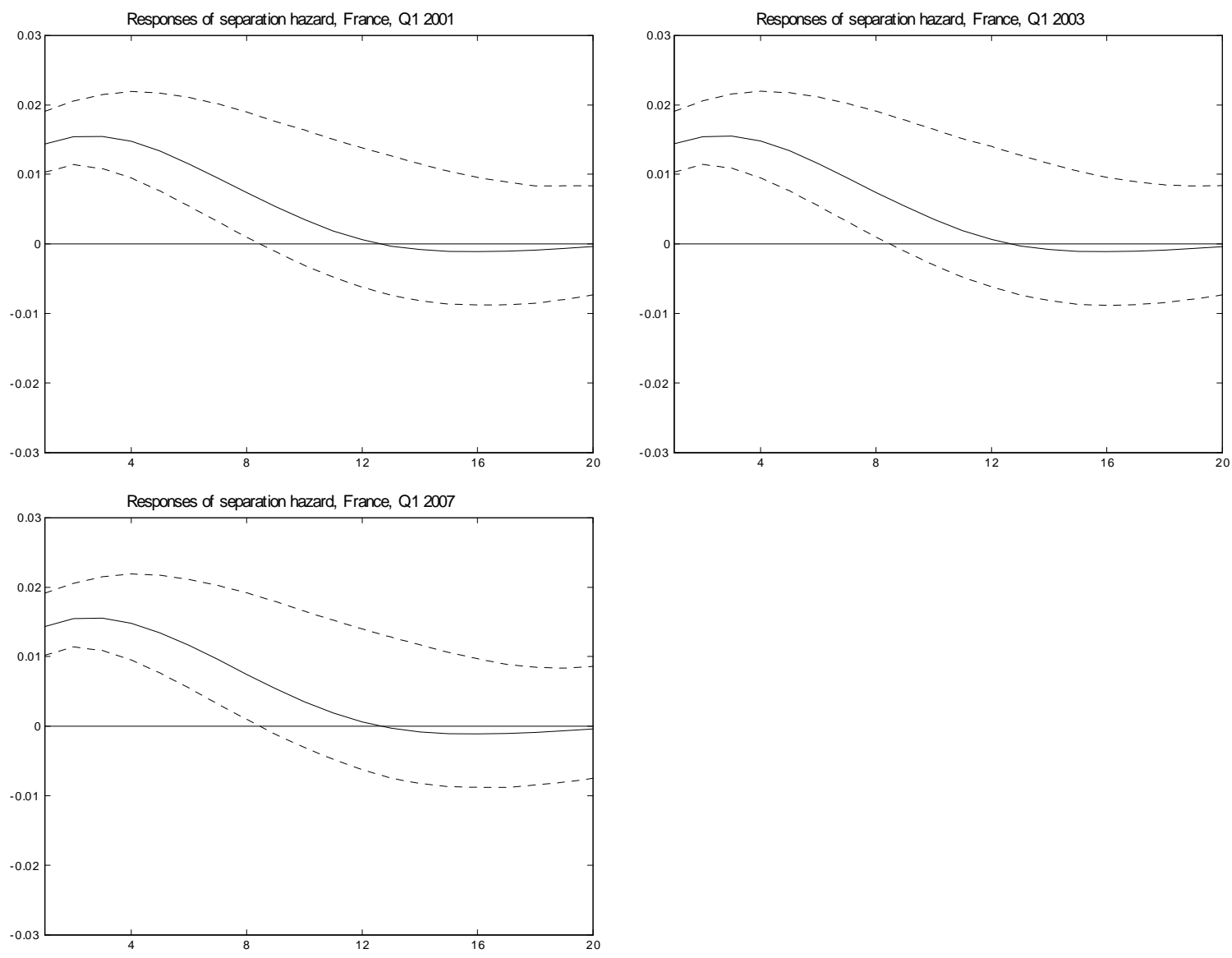

Figure 7. Impulse responses of separation hazards -Hete TVP-VAR, France 

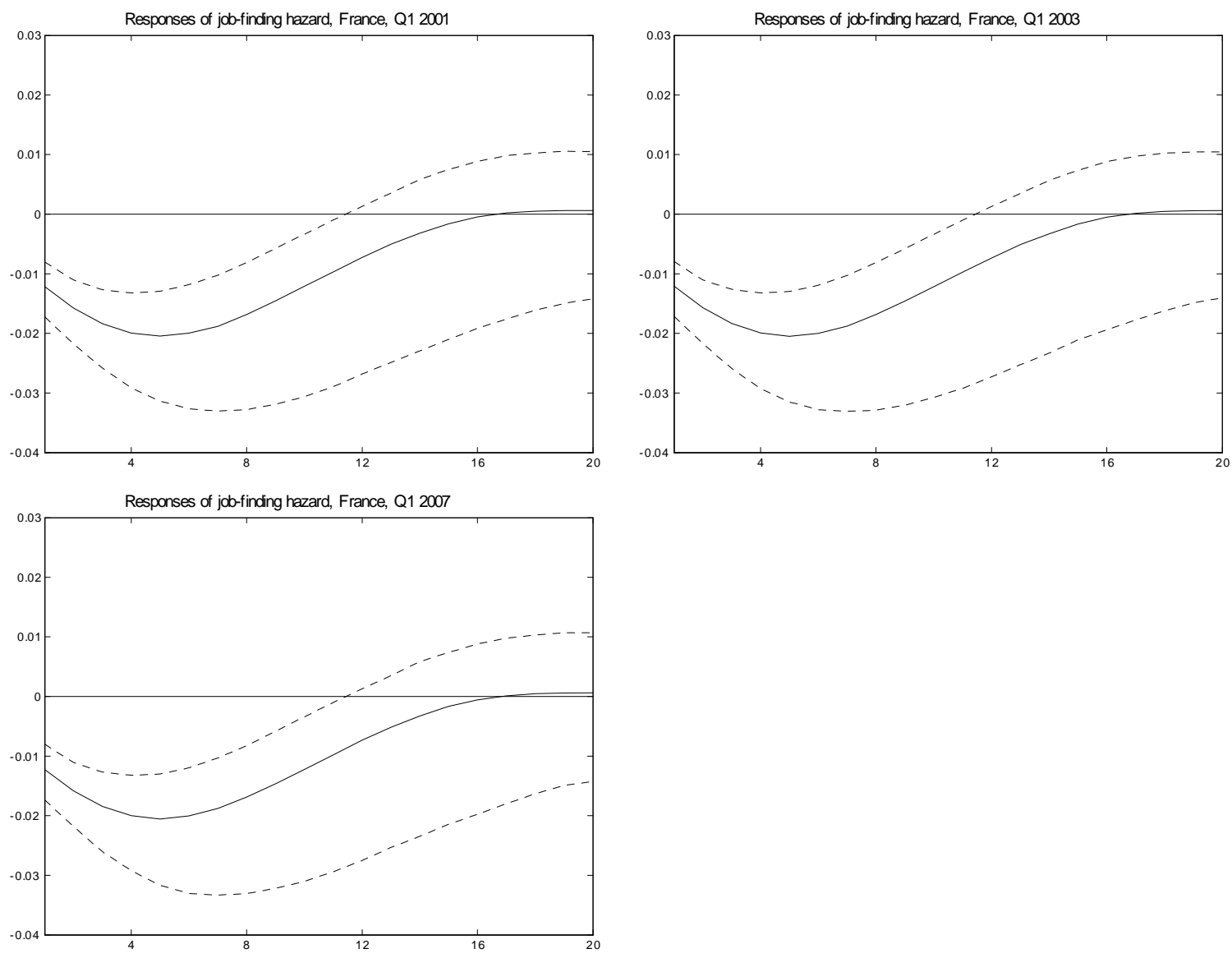

Figure 8. Impulse responses of job-finding hazards -Hete TVP-VAR, France 

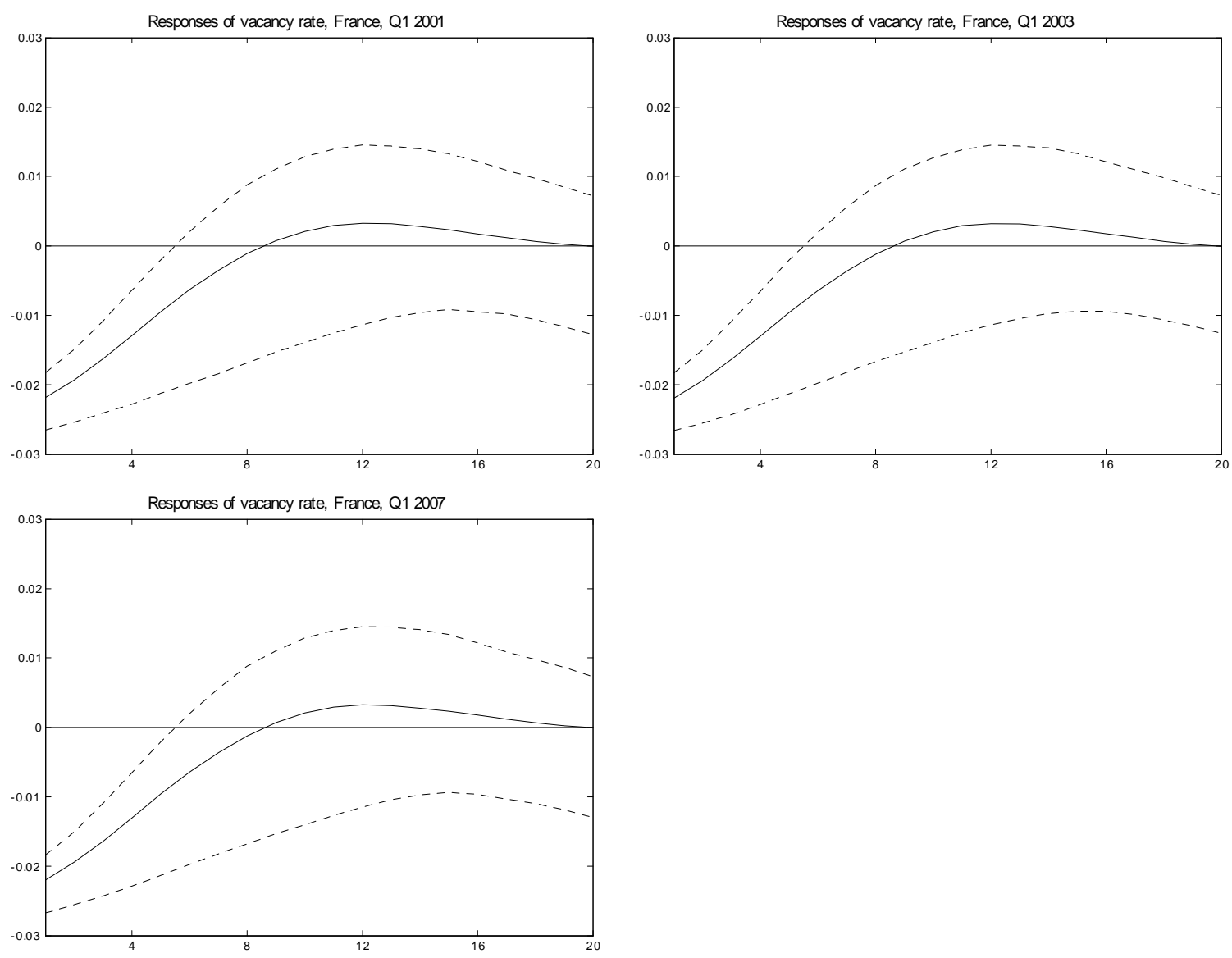

Figure 9. Impulse responses of vacancies -Hete TVP-VAR, France

\section{Spain}

The impulse responses for Spain are presented in Figures 10 to 12. The separation hazards display some time variability, which is revealed in the impulse response function at trough times tending to be quite different from those at peaks. The general pattern of the impulse responses also differ from those in other countries. For instance, in Spain, during trough periods the impulse response for the separation hazard increases initially in response to a shock and then declines slowly. The impulse response functions from trough periods are also quite persistent, since they are still relatively large after 20 quarters. 
In contrast, during peak periods the impulse responses decline after the initial shock and the decline occurs more quickly than during trough periods.

The impulse response functions for the job-finding hazard tend to start small before they reach a minimum and then recover. However, after about 6 quarters the impulse responses tend to plateau and the rate of decline is very slow, so that the impulse responses are still relatively large after 20 quarters. This suggests, not surprisingly, that there is a great deal of persistence in unemployment duration. As with the impulse response function for the separation hazard, the time variation in the impulse response for the job-finding hazard is most apparent in the results for 1995Q2 and 2001Q1, where the troughs in the impulse responses are much deeper and the level at which they plateau are much lower than in the other periods we consider.

The impulse response functions for the vacancy series also differ substantially from those in the US and Canada as well as France. In Spain, the shock to the vacancy rate is negative initially, but it does not decline a great deal because the impulse response is relatively stable through most of the 20 quarter horizon we consider. The impulse responses in Figures 10 to 12 suggest that there are significant differences between the process and dynamics of labor market adjustment in Spain relative to those in the other countries we consider. In particular, shocks to the labor market tend to be much more persistent and in many cases are still quite large 20 quarters out. This indicates that the process of labor market adjustment is much slower in Spain, relative to the other countries we consider. 

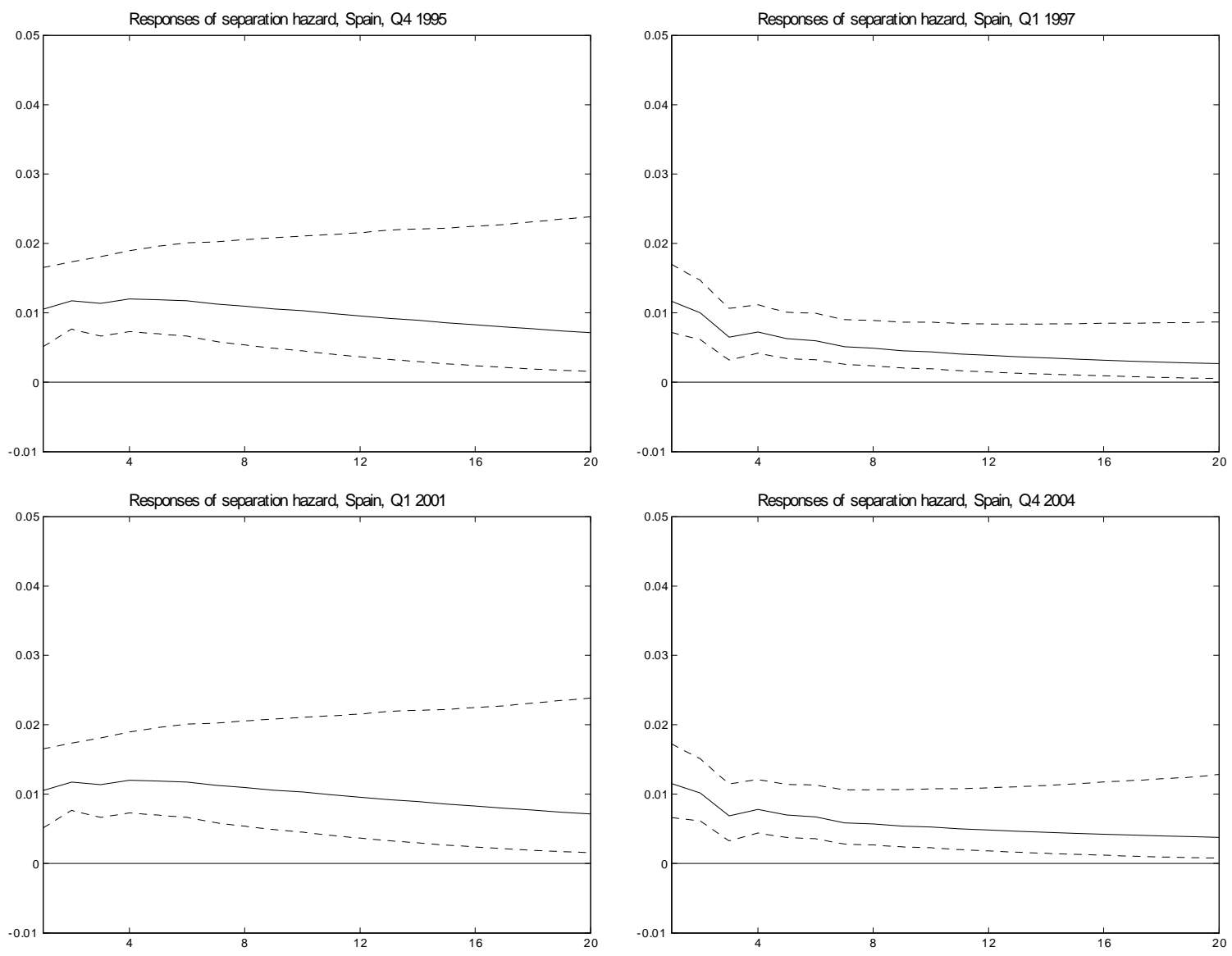

Figure 10. Impulse responses of separation hazards -Hete TVP-VAR, Spain 

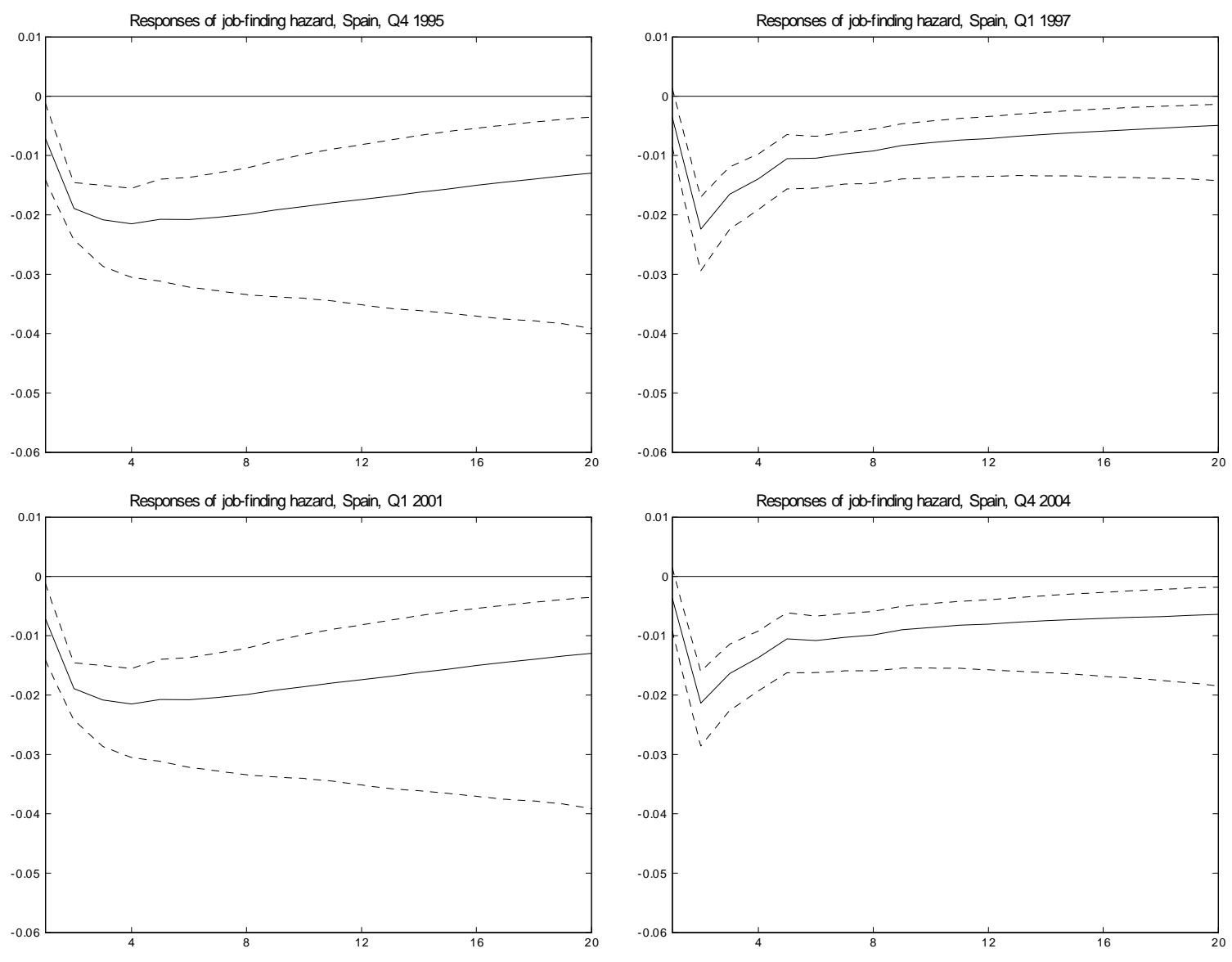

Figure 11. Impulse responses of job-finding hazards -Hete TVP-VAR, Spain 

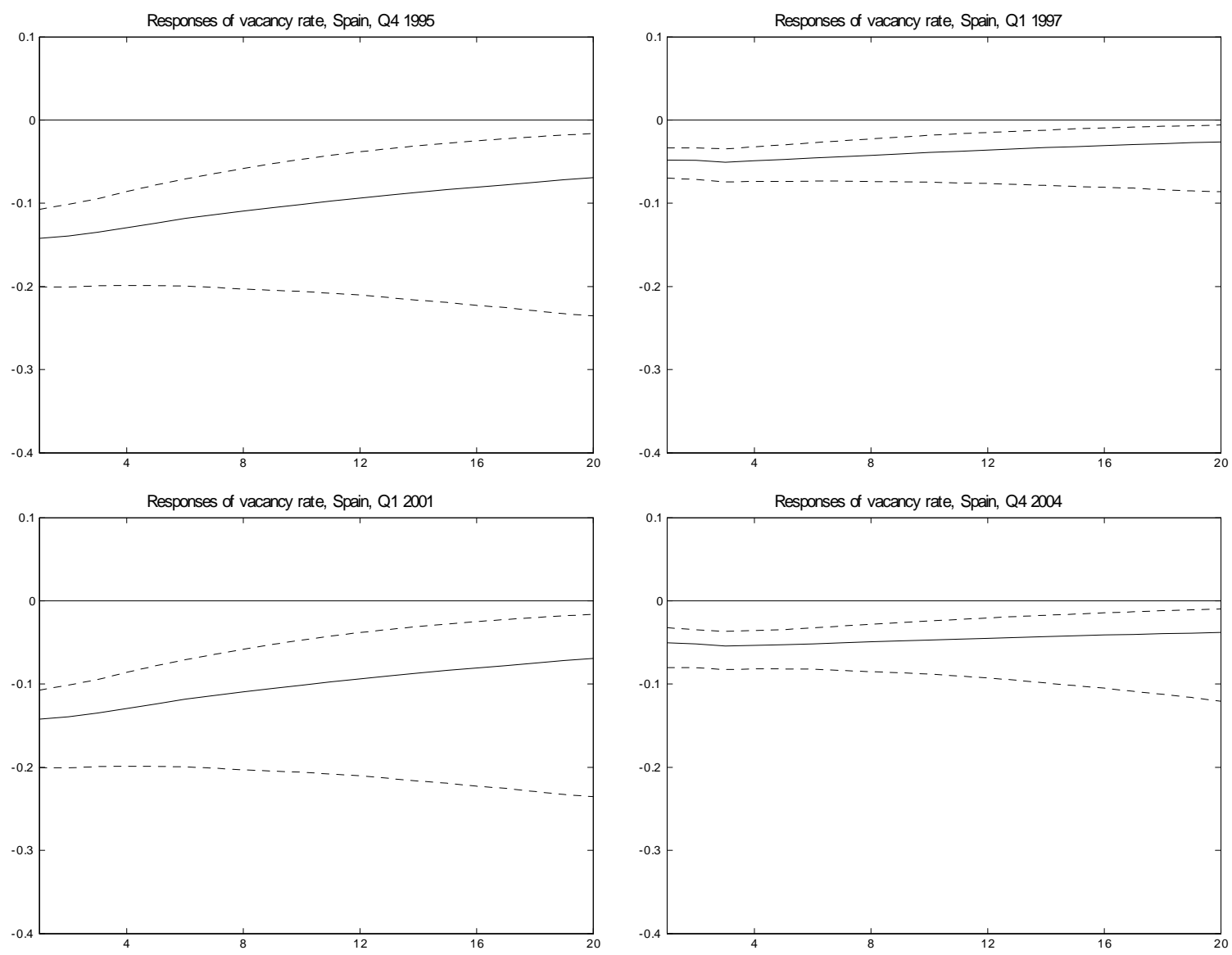

Figure 12. Impulse responses of vacancies -Hete TVP-VAR, Spain

\section{The UK}

The results for the UK are presented in Figures 13 to 15 . There is some time variability in the point estimates of the impulse responses for the UK. The impulse responses for separation hazard from the UK are slightly humped shaped, although the hump is very shallow. The decline in the impulse responses for the separation hazard from the UK is similar to that for Spain, since the decline is very slow. Even after 20 quarters impulse responses tend not to have returned to zero. The time variability in the separation hazard is revealed through a more pronounced hump shape during the cyclical trough 
periods we consider (1990Q4 and 2001Q1).

The impulse response functions for the job-finding hazard for the UK decline slightly before a beginning a slow recovery. This pattern is most clearly seen during 1990Q4 and 2001Q1, i.e., the cyclical troughs. The impulse responses for the job-finding hazard also decline very slowly and are still quite sizeable after 20 quarters.

The impulse responses for the vacancy rate display their variability via the initial response to a shock, which is much larger during the cyclical troughs. However, one common feature of the impulse responses for the vacancy rate during all the periods we consider is the amount of time it takes the shock to decline. Like the impulse responses for the separation and job-finding hazards in Figures 13 and 14, the impulse responses for the vacancy rate are still quite large after 20 quarters. 

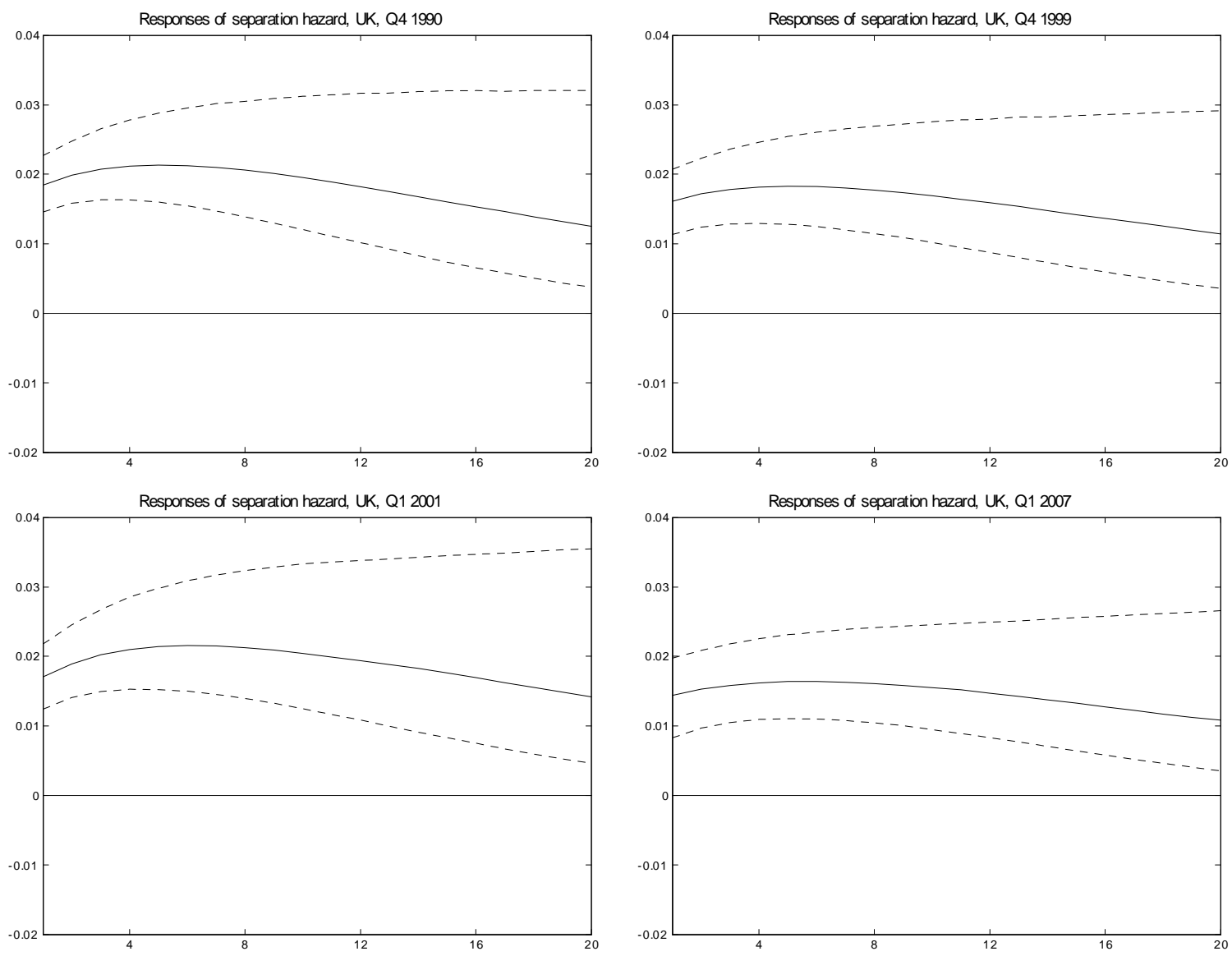

Figure 13. Impulse responses of separation hazards -Hete TVP-VAR, UK 

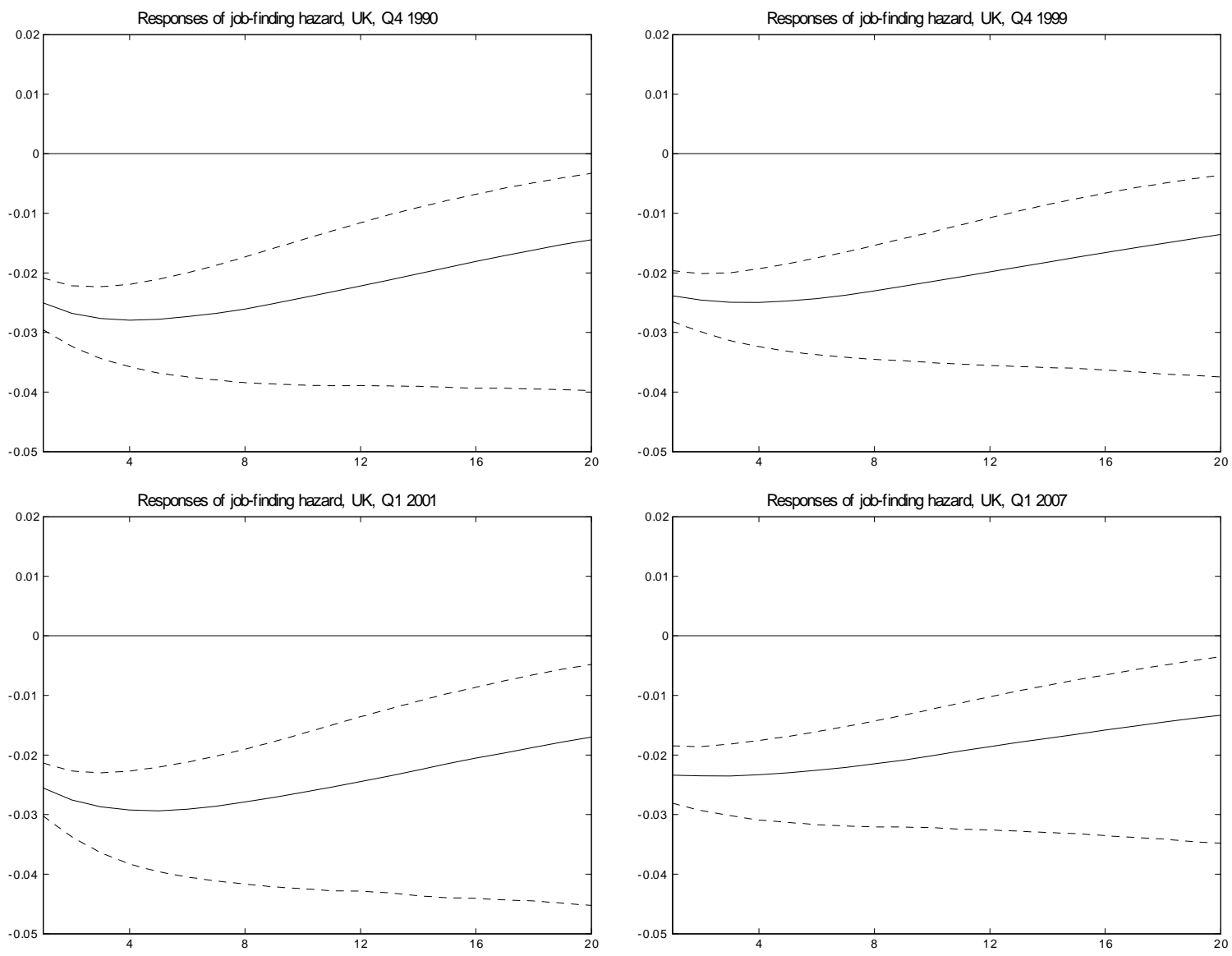

Figure 14. Impulse responses of job-finding hazards -Hete TVP-VAR, UK 

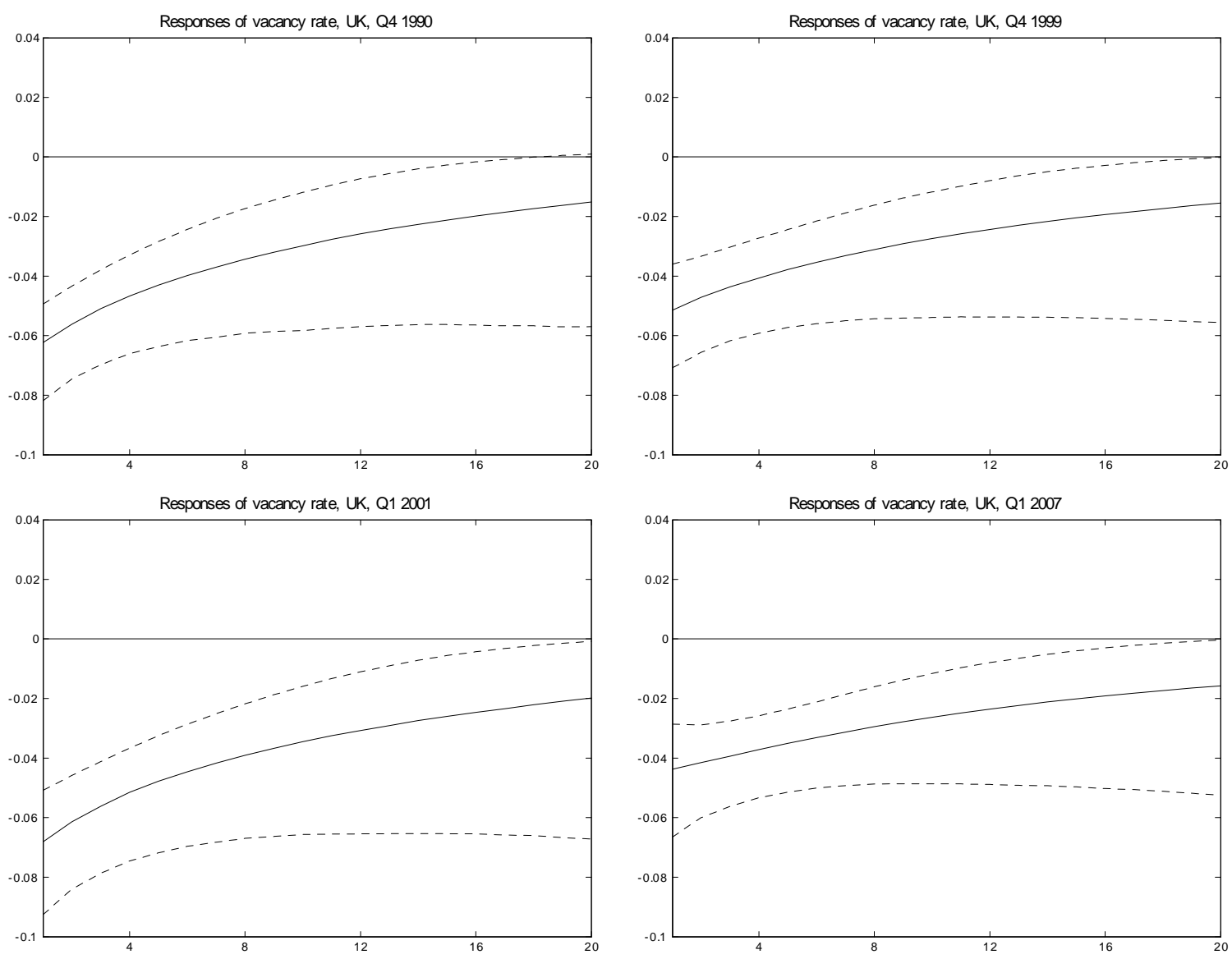

Figure 15. Impulse responses of vacancies -Hete TVP-VAR, UK

\section{Discussion}

The impulse response functions show that there are some cross-country differences in terms of how labor markets adjust. Elsby et al (2008), in their analysis of unemployment inflows and outflows in OECD countries, divided their study group into three blocks: Anglo-Saxon countries, which exhibit high separation rates and high job-finding hazards; Continental Europe, which has much lower separation and job-finding hazards relative to the Anglo-Saxon countries; Nordic economies, with fairly high separation and job-finding hazards; and, a few in- 
termediate cases, such as the UK which has hazard rates that lie about halfway between those in Continental European and Anglo-Saxon economies. ${ }^{10}$ Using this classification we see differences between the Anglo-Saxon countries in Elsby et al (2008), i.e., Canada and the US, and Continental European economies, i.e., France and Spain, in our study, and the UK. Our findings also suggest that the UK is not very similar to the US and Canada in terms of the process of labor market adjustment, despite having some similarities in the levels of the hazard rates to Canada and the US. Our findings also suggest that each of the European countries has its own distinctive features in terms of the process of labor market adjustment, which might be a reflection of the different institutional features of each country's labor market, such as differences in social insurance programs, laws governing labor standards, employment protection laws, trade union power and minimum wages (Machin and Manning, 1999, Nickell and Layard, 1999 and Blanchard and Wolfers, 2000).

Our results clearly indicate that there are some important differences in how labor market adjustments occur in the countries we include in our study. In the US and Canada, the impulse response functions for the job-finding hazard and vacancies have a hump shaped response, while separation hazard decreases after the initial shock. In Europe, we see differences in the impulse responses both relative to Canada and the US as well as across countries. As we noted above, these differences could reflect differences in the labor market institutions in each country. For example, in France the impulse responses for the job-finding hazard have a hump shape, while in the UK the impulse responses for the job-finding hazard tend to dip and then recover gradually (for the most part) and in Spain the impulse responses decline sharply, recover for a few quarters and then reach a semi-plauteau where they decline quite slowly. Our results also indicate that

\footnotetext{
${ }^{10}$ The classification in Elsby et al (2008) listed the Anglo-Saxon countries as Australia, New Zealand, Canada and the United States; the Continental European economies included, France, Spain, Germany, Italy, and Portugal.
} 
there are also differences in the persistence of shocks in Europe, with shocks declining more quickly in France than in Spain or the UK. In fact, in Spain and the UK these shocks are still quite large even 20 quarters out. We also observe much more time variability in the impulse responses for the European countries, since shocks can have much larger impacts during cyclical downturns. Another important difference between Europe and the US (except for the period we consider in the US Great Recession) as well as Canada is that impulse responses for shocks to all the series we consider are more persistent in Europe. This is especially true for Spain and the UK, where shocks to the job finding hazard are much more protracted and take a very long time to fade away, especially during recessions. These findings are consistent with observations others have made about the persistence of European unemployment (e.g., among others, Blanchard and Summers, 1986, Nickell and Layard, 1999 and Nickell et al, 2005).

We also find some interesting differences in the magnitude of the impulse responses for the separation and job-finding hazard, which imply differences in the contributions of unemployment incidence and duration to changes in unemployment across countries. Elsby et al (2008) in their analysis of the separation and job-finding hazards in the OECD countries found that the job-finding hazard has a larger contribution to changes in unemployment rates in the Anglo-Saxon economies (i.e., the US and Canada in our study), while the job separation hazard plays a larger role in continental Europe. We find that in the US and Canada the impulse responses for the job-finding hazard suggest that unemployment duration accounts for most of the changes in unemployment and this portion tends to increase as the impulse response horizon increases. The patterns we observe in Europe are very different. In France, there is a fairly even split between the impulse responses for the separation and job-finding hazards until 
about 4 to 6 quarters, after which the job-finding hazard effects tend to dominate more. In the United Kingdom, the impulse responses for the separation and job-finding hazard tend to be similar in the first few quarters, but the jobfinding hazard is more dominant after that. In Spain, the impulse responses for the job-finding and separation hazards vary much more over time and the business cycle. During cyclical troughs, the impulse responses for the separation and job-finding hazard are fairly similar, but the job-finding hazard becomes more dominant after a few quarters and remains so. In contrast, during cyclical peaks, the impulse responses for the separation hazard effects are larger for the initial few quarters, after which the job-finding hazard effects would become much larger for about 4 quarters. However, as the impulse responses for the job-finding hazard decline, they become similar in magnitude to the responses for the separation hazard, which suggests that they would account for similar shares of changes in unemployment at longer horizons. Our results for the US and Canada are in line with the conclusions in Elsby et al (2008) on the relative contributions of the separation and job-finding hazards to changes in unemployment. However, our TVP-VAR models allow us to observe two patterns that have not been noted before in the literature for Europe. First, our estimates indicate that there is time variation in these effects across countries and in most countries the job-finding hazard effects play a larger role in the intermediateand longer-run. Second, we observe some variation in these effects across the business cycle.

\section{Concluding Remarks}

In this paper, we have built on the existing literature which uses VAR methods for investigating the relationship between inflow and outflows into unemployment by using TVP-VAR methods. We use data from the US, Canada, France, 
Spain and the UK. Our analysis allows us to examine to extent of the crosscountry differences in how labor markets respond to shocks as well as whether these relationships are changing over time.

While we find that the process of labor market adjustment is similar in the US and Canada, we find that Europe is very different. Moreover, we find that the process for labor market adjustment also differs a great deal across the European countries we consider, i.e., each country has its own unique patterns in how adjustments occur. However, the common element across the European countries we consider is the much longer time for shocks to decline, relative to the US and Canada. We also find much more time variability in Europe, i.e., Spain and the UK. Interestingly, our analysis of the US during the Great Recession resembles some of the patterns we observe in the European economies we study, in terms of the amount it takes for shocks to disappear. Our estimates highlight the importance of using TVP-VAR models that can incorporate time variation since they reveal some features of the labor market adjustment process (particularly during severe economic downturns) that would not be captured by standard VAR models or more descriptive methods. 


\section{References}

Barnichon, R. (2010). "Building a composite help-wanted index." Finance and Economics Discussion Series 2009-35. Washington: Board of Governors of the Federal Reserve System.

Blanchard, O.J. and Summers, L.H. (2000). "Hysteresis and the European unemployment problem." NBER Macroeconomics Annual, 1, 15-78.

Blanchard, O.J. and Wolfers, J. (2000). "The role of shocks and institutions in the rise of European unemployment: The aggregate evidence," Economic Journal, 110, C1-C33.

Campolieti, M. (2011). "The ins and outs of unemployment in Canada, 1976-2008," Canadian Journal of Economics, 44, 1331-1349.

Campolieti, M. (2012). "The Canada-U.S. unemployment rate gap: A new look with a new decomposition for cross-country differences in unemployment rates," Canadian Public Policy, forthcoming.

Carlin, B. and Louis, T. (2000). Bayes and Empirical Bayes Methods for Data Analysis, second edition. Boca Raton: Chapman and Hall.

Cogley, T. and Sargent, T. (2001). "Evolving post World War II inflation dynamics," NBER Macroeconomics Annual, 16, 331-373.

Cogley, T. and Sargent, T. (2005). "Drifts and volatilities: Monetary policies and outcomes in the post WWII U.S.," Review of Economic Dynamics, 8, 262302.

Cogley, T., Morozov, S. and Sargent, T. (2005). "Bayesian fan charts for U.K. inflation: Forecasting and sources of uncertainty in an evolving monetary system," Journal of Economic Dynamics and Control, 29, 1893-1925.

D'Agostino, A., Gambetti, L. and Giannone, D. (2009). "Macroeconomic forecasting and structural change," ECARES working paper 2009-020.

Darby, M., Haltiwanger, J. and Plant, M. (1986). "The ins and outs of 
unemployment: The ins win," National Bureau of Economic Research, working paper 1997.

Elsby, M., Hobijn, B. and Sahin, A. (2008). "Unemployment dynamics in the OECD," National Bureau of Economic Research, working paper 14617.

Elsby, M., Michaels, R. and Solon, G. (2009). "The ins and outs of cyclical unemployment," American Economic Journal: Macroeconomics, 1, 84-110.

Elsby, M., Hobijn, B. and Sahin, A. (2010). "The labor market in the Great Recession," Brookings Papers on Economic Activity, Spring, 1-48.

Fortin, P. (1996). "The great Canadian slump," Canadian Journal of Economics, 29, 761-787.

Fujita, S. (2011). "Dynamics of worker flows and vacancies: Evidence from the sign restriction approach," Journal of Applied Econometrics, 26, 89-121.

Fujita, S. and Ramey, G. (2006). "The cyclicality of job loss and hiring," Federal Reserve Bank of Philadelphia, working paper \#06-17.

Fujita, S. and Ramey, G. (2009). "The cyclicality of separation and job finding rates," International Economic Review, 50, 415-430.

Hall, R. (2005). "Employment efficiency and sticky wages: Evidence from flows in the labor market," Review of Economics and Statistics, 87, 397-407.

Koop, G. and Potter, S. (1999). "Dynamic asymmetries in U.S. unemployment," Journal of Business and Economic Statistics, 17, 298-312.

Koop, G., and Korobilis, D. (2009). "Bayesian multivariate time series methods for empirical macroeconomics," Foundations and Trends in Econometrics, $3,267-358$.

Koop, G., Leon-Gonzalez, R. and Strachan, R. (2009). "On the evolution of the monetary policy transmission mechanism," Journal of Economic Dynamics and Control, 33, 997-1017.

Machin, S. and Manning, A. (1999). "The causes and consequences of long- 
term unemployment in Europe." In Handbook of Labor Economics, Volume 3C, ed. O. Ashenfelter and D. Card. Amsterdam: North Holland.

Macklem, T. and Barillas, F. (2005). "Recent developments in the CanadaUS unemployment rate gap: Changing patterns in unemployment incidence and duration," Canadian Public Policy/Analyse de Politiques, 31, 101-107.

Nickell, S. and Layard, R. (1999). "Labor Market Institutions and Economic Performance." In Handbook of Labor Economics, Volume 3C, ed. O. Ashenfelter and D. Card. Amsterdam: North Holland.

Nickell, S., Nunziata, L. and Ochel, W. (2005). "Unemployment in the OECD Since the 1960s, What Do We Know?" Economic Journal, 115, 1-27.

Paustian, M. (2007). "Assessing sign restrictions." B.E. Journal of Macroeconomics (Topics), 7, article 23.

Petrongolo, B. and Pissarides, C. (2008). "The ins and outs of European unemployment," American Economic Review, 98, 256-262.

Primiceri, G. (2005). "Time varying structural vector autoregressions and monetary policy," Review of Economic Studies, 72, 821-852.

Riddell, W. (2005). "Why is Canada's unemployment rate persistently higher than in the United States," Canadian Public Policy/Analyse de Politiques, 31, 93-100.

Shimer, R. (2007). "Reassessing the ins and outs of unemployment," $N a-$ tional Bureau of Economic Research, working paper 13421.

Skalin, J. and Teräsvirta, T. (2002). "Modeling asymmetries and moving equilibria in unemployment rates," Macroeconomic Dynamics, 6, 202-241.

Sims, C. (1980). "Macroeconomics and reality," Econometrica, 48, 1-48.

Stock, J. and Watson, M. (1996). "Evidence on structural instability in macroeconomic time series relations," Journal of Business and Economic Statistics, 14, 11-30. 
Sunter, D., Kinack, M., Akyeampong, E. and Charette, D. (1997). "The Labour Force Survey: Development of a new questionnaire for 1997," Statistics Canada: Household Surveys Division.

Uhlig, H. (2005). "What are the effects of monetary policy on output? Results from an agnostic identification procedure," Journal of Monetary Economics, 52, 381-419. 